Nuntius Antiquus, Belo Horizonte, v. 12, n. 2, p. 289-302, 2016

\title{
Desejo e fúria de Ovídio pelas tabelas: Amores 1.11 e 1.12
}

\section{Ovid's desire and fury by the tablets: Amores 1.11 and 1.12}

\author{
Brunno Vinícius Gonçalves Vieira \\ Universidade Estadual Paulista "Júlio de Mesquita Filho" \\ Araraquara, São Paulo / Brasil \\ brunnovgvieira@gmail.com
}

Resumo: Apresenta-se, neste artigo, a tradução do díptico (Amores $1.11 \mathrm{e}$ 1.12) precedida de uma introdução em que o tradutor busca apresentar as motivações práticas e teóricas subjacentes à sua execução. Desenvolve-se uma breve reflexão sobre a duplicidade e a desigualdade tanto dos versos quanto dos personagens que vivem duas diferentes situações de uma fábula amorosa. O díptico oferece dois lances opostos de uma tentativa de amor, sua esperança e seu fracasso. Desejava o poeta se declarar. Desejava o encontro. Desejava Amor em seu sentido carnal (1.11), mas recebe a negativa, caindo em fúria, não contra a amada, mas contra as dúplices tabuinhas (1.12), sendo essas últimas mais uma metonímia da dubiedade do gênero elegíaco como praticado por Ovídio. A tradução, em uma estrofe portuguesa composta por dois decassílabos seguidos de um hexassílabo, procura replicar poeticamente alguns aspectos sonoros, sintáticos e semânticos percebidos no texto de partida.

Palavras-chave: elegia erótica; duplicidade; tradução; Ovídio.

Abstract: In this paper, the Portuguese translation of the diptych (Amores 1.11 e 1.12) is presented with a foreword in which the translator shows his practice and theoretical motivations to his translation's work. One develops a short essay about the doubleness and inequality of lines and personae which live two different situations in the affairs of love. The diptych shows two opposite incidents of an attempt of love: his hope and his failure. The poet wanted to declare his love. He wanted a date. He wanted the presence of Love in his 
sexual sense (1.11); he received, however, a denegation and then fell in fury not against his beloved girl, but against the double tablets (1.12). These tablets are another metonymy of the generic doubleness as exercised by the elegist Ovid. The translation, in a Portuguese stanza composed with two decasyllabes and one hexasyllabe verse, seeks to reply poetically some aspects of sound, sintax and meaning present in the source text.

Keywords: erotic elegy; doubleness; translation; Ovid.

Recebido em 8 de abril de 2016. Aprovado em 24 de agosto de 2016.

$*$

Ovídio, naquela sua famosa elegia autobiográfica (Tr. 4.10), fala sobre como que, de geração espontânea, saíam-lhe os versos no início de sua carreira literária:

Sponte sua carmen numeros ueniebat ad aptos, et quod temptabam scribere uersus erat. (Ov. Tr. 4.10.25-6)

O carme vinha-me espontâneo em metros justos, e o que escrever propunha em verso vinha.

Não é possível que nos enganemos com essa vaidosa autoafirmação, à vista de Amores, seu primeiro livro de poemas. A requintada arquitetura dessa obra tanto no microcosmo de cada verso, como na sucessão de poemas, faz-nos suspeitar dessa ingênua evocação da abiogênese. Trata-se de versos esmeradamente burilados no nível do som e na concatenação das palavras, os quais não deixam dúvida quanto a um criterioso trabalho de reelaboração e revisão. Em 1.11 e 1.12, que estarão sob leitura e tradução neste artigo, tanto esse critério quanto esse trabalho se dão a ver.

Ovídio, neste díptico, ou seja, neste par de poemas que apresentam um esquete dramático ou que variam sobre um mesmo tema (MCKEOWN, 1989, p. 390), oferece um esmerado trabalho poético (fono-sintático-semântico) em que as tabelas pelo amante endereçadas à amada incorporam uma sofisticada metapoesia. 
A elegia erótica romana toda, ou quase toda (há casos de poemas meramente ecfrásticos e quase impessoais), é produto de um eu enunciador que busca maldizer ou convencer a puella do amor-oximoro que este mesmo eu professa performaticamente (odi et amo/ sentio et excrucior, cf. Catulo, 85) em versos de dois a dois como casais, dois díspares seres desiguais, hexâmetro e pentâmetro. No dístico elegíaco, a desigualdade de versos emparelhados lembra a desigualdade de destinos dos pares amorosos quase sempre saudada ou rechaçada: auspicii numerus non erat ipse boni, "não dá sorte o que é par!" $(1.12,28) .{ }^{1}$ Esse díptico, então, desigual como a estrofe em que é vazado, ${ }^{2}$ ou mesmo, uma projeção macroestrutural da dupla natureza íntima de seus versos, sequencia esperança e fracasso de uma tentativa de amor. Desejava o poeta se declarar. Desejava o encontro. Desejava Amor em seu sentido carnal (1.11), mas recebe a negativa, caindo em fúria, não contra a amada, mas contra as dúplices tabuinhas (1.12), sendo essas últimas mais uma metonímia da dubiedade que o gênero lhe acomete.

O díptico se constrói pelas tabelas. É bom lembrar a alta tecnologia que elas prefiguram como tablets a figurariam hoje, embora rapidamente (somos tragicamente mais rápidos!) o celular já faça mais que o tablet e, ao dizer isto aqui, eu já prevejo uma breve data de vencimento para

\footnotetext{
${ }^{1}$ Permito-me aqui a interpretação de McKeown (1989, p. 335): "O pentâmetro parece oferecer uma algo desnecessária explicação do gracejo presente em duplices [acrescento: ao mesmo tempo duplas e dúbias...]. Trata-se de um particularmente claro exemplo da função subalterna do pentâmetro de resgatar um dado ponto desenvolvido no hexâmetro". Na minha leitura, a ideia de o número par (também prevista em duplex no OCD 4b, duplicis ... palmas) não ser auspicioso também é uma tentativa de leitura intertextual com o famoso hemistíquio virgiliano [numero] deus impare gaudet, tentando manter a síntese de Raimundo Carvalho: "A deus apraz o ímpar" (Vir. E. 8.75). Os versos e as tabuinhas são de dois em dois (pares). No caso do dístico, formado por um hexâmetro e um pentâmetro, o fato de serem dois e ao mesmo tempo desiguais está em sua essência, como se pode flagrar na definição de Horácio uersibus impariter iunctis (“em versos jungidos de modo desigual", cf. Hor. Ars, 75). Agradeço a sensível leitura do parecerista anônimo da revista que me levou a esclarecer este ponto do texto.

${ }^{2}$ Tomei o entendimento do caráter estrófico dessa mínima série de versos de Prado (1997, p. 157): "Essa unidade da poesia elegíaca tende, pelo uso com que a consagraram os poetas que nela se expressaram, a encerrar um enunciado linguístico de sentido completo, razão pela qual se poderia atribuir-lhe, sem mais, um sentido estrófico em relação ao todo que é o poema".
} 
esta minha avaliação tecnológica... É possível afirmar, se se concordar com a conjectura de McKeown sobre uma relação intertextual entre este "endereçamento" amoroso presente especialmente em 1.11 e uma elegia de Meleagro AP 5.182 (1989, p. 308), que o(s) poema(s) de Ovídio denotam uma evolução na correspondência amorosa (mas também na sua escritura), uma vez que o poeta elegíaco helenístico pressupõe que sua criada, chamada Dorcás, memorize as palavras do amante. Reproduzo a tradução de Luiz Carlos André Mangia Silva: ${ }^{3}$

Vai dizer-lhe isto, Dorcás:

escuta, dize-lhe duas, três vezes repete tudo.

Mas vai correndo, Dorcás,

não fiques parada, voa.

Espera, Dorcás, espera:

por que te apressas, Dorcás,

antes que saibas de tudo?

Junta ao que falei há pouco...

melhor... que tolices digo?

Não, não digas nada disso,

mas apenas... Dize tudo.

Não deixes de dizer nada.

Mas por que razão, Dorcás,

eu te envio - se eu próprio (olha!)

vou seguindo à tua frente? ${ }^{4}$

(Trad. Luiz Carlos A. M. Silva)

\footnotetext{
${ }^{3}$ Agradeço a cessão do tradutor, que é professor da Universidade Estadual de Maringá, de uma de suas traduções inéditas do livro quinto da Antologia Palatina, ainda inédito. Ademais, a proposta de Silva de traduzir o dístico por quadras em heptassílabos brancos, enriquece nosso repertório de soluções para traduzir o dístico elegíaco.

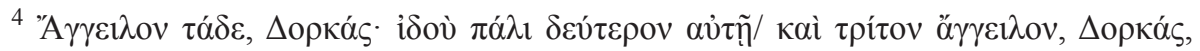

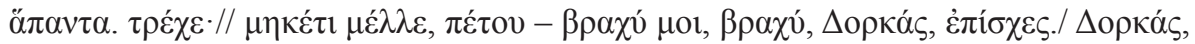

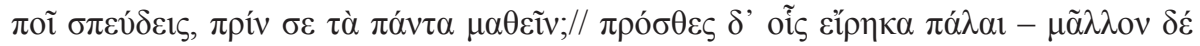

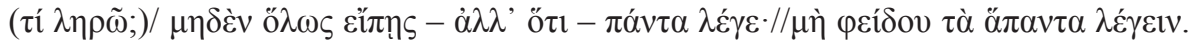

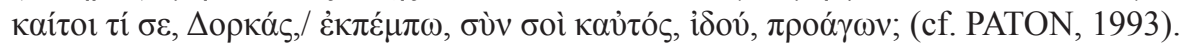




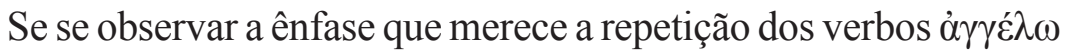
(literalmente, "dizer como mensageiro", daí "anunciar" nos vv. 1 e 2) e,

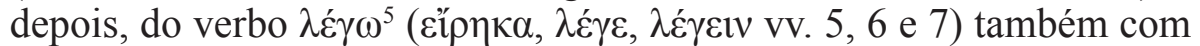
o sentido primeiro de "dizer", o mundo helenístico de Meleagro ( $c a .100$ a. C.), que se compraz do avanço no uso e no valor material da escrita, ${ }^{6}$ ainda não o havia consolidado nas práticas amorosas como o contraste com a cena elegíaca de Ovídio bem evidencia. ${ }^{7}$ Neste último caso, o suporte da escritura registra um desenvolvimento também das relações amorosas. Em oposição aos verbos de "dizer" em grego, há o intercurso das tabelas. À criada não se exige mais o "aprender de cor" pressuposto pelo verbo $\mu \alpha v \theta \alpha ́ v \omega(\mu \alpha \theta \varepsilon \tilde{v}$, v. 4), mas sim que ela faça chegar a mensagem escrita (tabellas/perfer, cf. 1.11,7-8), cuja configuração na escolha das palavras e na própria face-página da tabuinha é de inteira responsabilidade do poeta-amante.

Como signo de novidade e, por que não, de inovação (embora esse termo quase sempre não me parece cheirar bem), os pequenos pedaços de tábuas retangulares e enceradas em que se escrevia com o stylus (estilete) aparecem em vários afrescos romanos. Entre eles escolho a célebre imagem pompeiana aproveitando-me também da poética descrição que dela faz Paul Veyne:

\footnotetext{
${ }^{5}$ É bom lembrar de que $\lambda \varepsilon ́ \gamma \omega$ está na raiz do latino legere, mas sem a pontual relação com a escrita que o verbo consolidou em seu sentido lato: fac tamen illa legat, cf. 1. 11,16; perlectis rescribat, cf. 1.11,16.

${ }^{6}$ Até mesmo como mancha no "papel", como pressupõem os engenhos da "poesia para ver", ou seja, a prática do tekhnopaígnion (DEZOTTI, 2010).

${ }^{7}$ Em conversa com Jacyntho Lins Brandão sobre a evolução da escrita e das tabuinhas na Grécia, ele generosamente me apresentou o livro de Irigoin sobre o tema. De fato, esse instrumento de registro da escrita é testemunhado já em Homero (Il. 6.167-70, cf. IRIGOIN, 2001, p. 12), quando Próito envia ao rei da Lídia uma mensagem imprecando

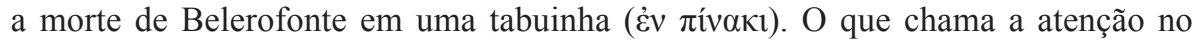
contexto romano, portanto, é seu uso cotidiano na troca de mensagens escritas entre homens e mulheres.
} 


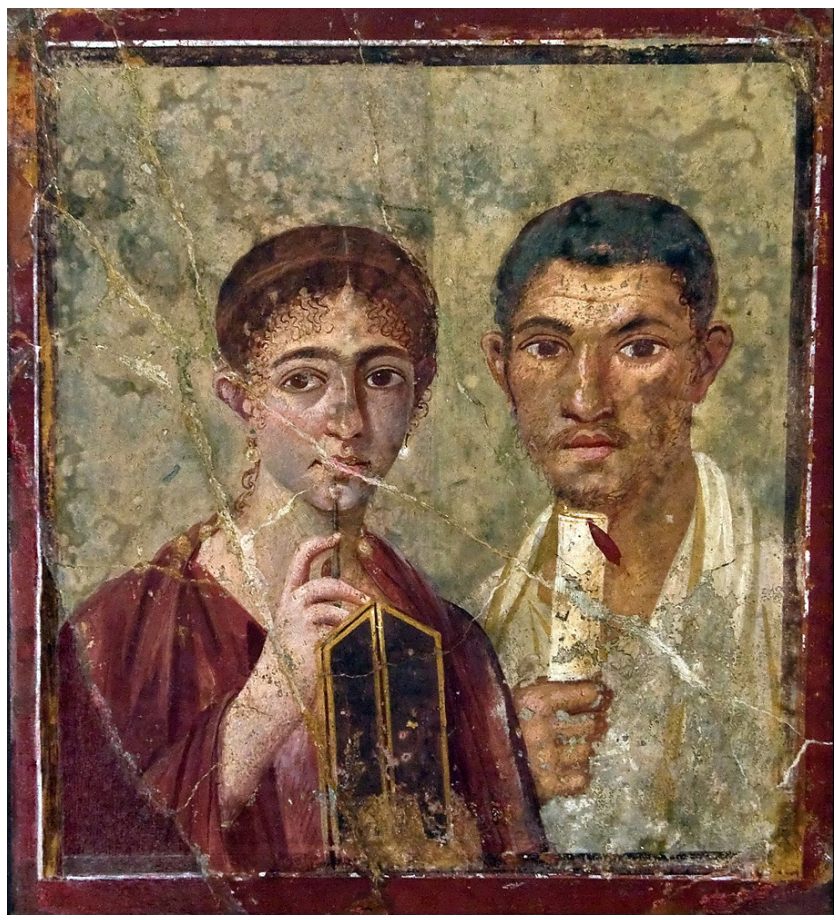

FIGURA 1 - Páquio Próculo e sua esposa

O marido e a mulher detêm os atributos menos contestáveis e mais pessoais de sua superioridade social; não a bolsa ou a espada, atributos da riqueza e do poder, mas um livro, tabuinhas de escrever e um estilete. Esse ideal de cultura é natural: o livro e o estilete visivelmente são para eles instrumentos familiares, que o casal não ostenta. Coisa bastante rara na arte antiga, que não aprecia os gestos familiares, o homem expectante apoia o queixo no livro (em forma de rolo), e a mulher pensativa leva o estilete aos lábios: procura um verso, pois a poesia também é uma arte das damas. (VEYNE, 2009, p. 20)

Imaginemos que ela estivesse pensando para responder a Nasão... ao amante, que suplica um encontro por intermédio da sua cabeleireira, a criada Nape (e vejam como, no afresco, os cabelos da jovem senhora 
estão bem postos). Apenas supondo, pois não podemos muito diante das fantasias ovidianas, nem das nossas. Esses dois poemas de Ovídio encenam, por conseguinte, um esquete em que um amante envia à amada, por escrito, através de sua criada, uma proposta de encontro (1.11) que lhe é negada por circunstâncias não reveladas (1.12).

O primeiro poema é sobre o desejo e a esperança, terminando com a possibilidade de fazer das tabelas ex-votos no templo de Vênus. O segundo sobre a fúria da recusa, com uma longa sequência de vitupério contra as tabelas. Assim, ambos colocam em cena o ato de escrever, os objetos relacionados a esta prática (tabelas), a superfície a ser preenchida, as letras, os rabiscos, etc. Trata-se de escrita poética. Trata-se de criação verbal à qual a evocação da imagem acima é só uma ilustração sob minha irresponsabilidade. Tudo é palavra, tabelas, proposta e recusa.

Mas como fugir do óbvio conteúdo ou do exemplo imagético em palavra? Como dar a entender que Ovídio burilou tais versos com excelência para que eles fossem mais do que retrato, para que eles fossem pura metalinguagem? Como revelar os avanços no design da escritura somados ao fluido e volátil significante? Essa fuga e essa tentativa de transformar o mero conteúdo em poesia foi o que procurei ao traduzir. Walter Benjamin em seu célebre ensaio "A tarefa do tradutor" entendeu que a tradução é uma forma, cito, "Übersetzung ist eine Form, e para apreendê-la como tal, é preciso retornar ao original. Pois nele reside a lei dessa forma, enquanto encerrada em sua traduzibilidade" (BENJAMIN, 2010, p. 205). Benjamin também formula neste texto a ideia de que a tradução é aquela que pretende resgatar a língua pura da poesia:

Nas línguas tomadas isoladamente, incompletas, aquilo que é visado nunca se encontra de maneira relativamente autônoma, como nas palavras e frases tomadas isoladamente; encontra-se em constante transformação, até que da harmonia de todos aqueles modos de visar ele consiga emergir como pura linguagem. (BENJAMIN, 2010, p. 213)

O que ensaio aqui nesta tradução dos dois poemas, é uma forma (composta de dois decassílabos seguidos de um hexassílabo, buscando imitar uma matriz estrófica utilizada algumas vezes por Tomás Antônio Gonzaga em Marília de Dirceu - ainda que, à diferenç,a do modelo 
gonzaguiano, eu tenha me servido de versos brancos, como pensado por Márcio Thamos em versões já publicadas na revista Letras Clássicas) ${ }^{8}$ que recrie, sonhando concretamente com a utopia de uma Língua Pura, adâmica, o jogo sonoro e sintático que fui capaz de ler no original, a partir do texto da Teubner, editado por Antonio Ramirez de Verger (2006) e com o suporte do comentário de McKeown (1989).

Na minha prática tradutória, tenho entendido que tangemos mais ou menos felizmente laivos de lábios da Língua pura benjaminiana, quando ficamos atentos à recriação sonora (melopeia) e sintático-estrutural (logopeia) no dizer de Pound, que é como consigo, modernamente e um tanto pós-estruturalmente, descrever os trabalhos hercúleos de linguagem poética de Ovídio. Tenho pensado muito no Saussure noturno e um tanto starobinskiano de As palavras sob as palavras (STAROBINSKI, 1971). Tenho pensado muito no princípio da reiteração assonântica e aliterante que provém do original latino. Se consigo, através destas práticas, tanger algo do texto de partida, isso ficará ao leitor desses versos que fiz em resposta a Ovídio. Tinha traduzido tabela inicialmente por "tabuinha", mas atento ao som e à música dele resultante, julguei que a literalidade aqui também rememorava a expressão reconhecível especialmente a partir da música "pelas tabelas" de Chico Buarque, até porque o eu poemático anda nestes dois poemas caindo pelas tabelas, como muitos de nós em tempos de ofensas à democracia e às liberdades individuais garantidas por nossa constituição.

Seguem as traduções que são a realização desse ideário aqui brevemente exposto.

\section{Amores, 1.11}

Colligere incertos et in ordine ponere crines docta neque ancillas inter habenda Nape, inque ministeriis furtiuae cognita noctis utilis et dandis ingeniosa notis, saepe uenire ad me dubitantem hortata Corinnam, saepe laboranti fida reperta mihi,

\footnotetext{
${ }^{8}$ Cf. Uma breve explanação sobre a constituição desta estrofe em Thamos (2011, p. 217). Embora, à diferença de Thamos, nos meus experimentos neste padrão, não me obriguei a usar a sequência do heroico (com acento na sexta sílaba) no segundo dos decassílabos.
} 
accipe et ad dominam peraratas mane tabellas

perfer et obstantes sedula pelle moras.

nec silicum uenae nec durum in pectore ferrum

nec tibi simplicitas ordine maior adest.

credibile est et te sensisse Cupidinis arcus:

in me militiae signa tuere tuae.

si quaeret quid agam, spe noctis uiuere dices:

cetera fert blanda cera notata manu.

dum loquor, hora fugit: uacuae bene redde tabellas,

uerum continuo fac tamen illa legat.

adspicias oculos mando frontemque legentis:

et tacito uultu scire futura licet.

nec mora, perlectis rescribat multa, iubeto:

odi, cum late splendida cera uacat.

comprimat ordinibus uersus, oculosque moretur

margine in extremo littera rasa meos.

Quid digitos opus est graphium lassare tenendo?

hoc habeat scriptum tota tabella 'ueni!'

non ego uictrices lauro redimire tabellas

nec Veneris media ponere in aede morer. subscribam VENERI FIDAS SIBI NASO MINISTRAS

DEDICAT, AT NUPER VILE FUISTIS ACER.'

\section{Amores, 1.11}

Em prender fios revoltos, recompondo-lhes,

Nape, és perita, e indigna de constar

no rol das serviçais,

e dos ofícios da furtiva noite

sábia, e, na entrega urgente de mensagens,

és hábil, prestimosa,

ora exortas que a mim procure a oblíqua

Corina, ora, fiel comparsa, encontro-te, quando o sofrer me esfalfa, aceite e à dona entrega cedo em mãos tabelas plenas! Fica, pois, atenta em abolir delongas. 
Nem pétreo sangue trazes, nem de ferro é teu peito; como outras de tua classe, simples demais não és.

Pode-se crer que de Cupido o arco já sentiste e, sendo eu da tua tropa, protege-me as insígnias.

Se ela indaga o que faço, dirás "vive na esperança da noite". A cera narra

o mais em brandos traços.

Quanto falo! A hora corre. Ei-la só. Vai, dá-lhe as tabelas! Faz com que, no entanto, ela leia de pronto.

Peço que observes da leitora os olhos, o rosto. É lícito saber em tácita feição coisas futuras.

A tudo, sem demora, que ela leia; resposta, então, exijo, e farta: odeio brilho de cera intacta!

Que esprema linha em linha! Que a lavrada letra, das margens bem na extremidade, os olhos embarace-me!

O quê!? Exaurir os dedos no estilete será preciso? Basta escrever isto de fora a fora: "VEM!"

Não tarda, vou coroar de louro as tábuas triunfantes, e ao centro do venéreo templo depositá-las com a inscrição: "A VÊNUS, NASÃO SAGRA ESTAS FIÉIS MINISTRAS, VÓS, QUE, HÁ POUCO, FOSTES MEROS MADEIROS".

\section{Amores, 1.12}

Flete meos casus: tristes rediere tabellae!

infelix hodie littera posse negat. omina sunt aliquid: modo cum discedere uellet, ad limen digitos restitit icta Nape. missa foras iterum limen transire memento 
cautius atque alte sobria ferre pedem!

Ite hinc, difficiles, funebria ligna, tabellae, tuque, negaturis cera referta notis, quam, puto, de longae collectam flore cicutae melle sub infami Corsica misit apis.

at tamquam minio penitus medicata rubebas:

ille color uere sanguinolentus erat.

proiectae triuiis iaceatis, inutile lignum, uosque rotae frangat praetereuntis onus!

illum etiam, qui uos ex arbore uertit in usum,

conuincam puras non habuisse manus.

praebuit illa arbor misero suspendia collo, carnifici diras praebuit illa cruces;

illa dedit turpes raucis bubonibus umbras, uulturis in ramis et strigis oua tulit.

his ego commisi nostros insanus amores molliaque ad dominam uerba ferenda dedi? aptius hae capiant uadimonia garrula cerae, quas aliquis duro cognitor ore legat; inter ephemeridas melius tabulasque iacerent, in quibus absumptas fleret auarus opes.

ergo ego uos rebus duplices pro nomine sensi. auspicii numerus non erat ipse boni. quid precer iratus, nisi uos cariosa senectus rodat, et inmundo cera sit alba situ?

\section{Amores, 1.12}

Minha sina chorai! Voltaram, tristes, as tabelas! A letra lastimosa declara: "Hoje não posso". Maus agouros existem: porque Nape, topando o umbral da porta, tropicou, ao decidir sair.

Da outra vez em que a porta atravessares, lembra, ó Nape, de estar sóbria e de o pé 
erguer mais alto e atento!

Vós, tabelas cruéis, lenho funéreo, ide embora e levai, toda de nãos

rabiscada, esta cera, favo de flor de cicuta, eu bem sei, que uma abelha da Córsega cobriu com um mel de má-fé!

Eras vermelha, cera, qual retinta apenas por zarcão, mas, em verdade,

teu corante era sangue.

Dejetos vis, na rua jazereis, e que da roda o peso vos reduza

a estilhaços de pau.

Quem de árvore tornou-vos utensílio, ele, tal como vou prová-lo agora, mãos puras não possui.

Serviu de forca a um infeliz pescoço e deu infames cruzes ao carrasco

o tronco que vos trouxe. Viestes de árvore que ao rouco mocho, que à coruja e ao abutre, aves de agouro, deu ninho e esconderijo.

A estas confiei nossos amores, que insano eu sou!, via tabelas, dei à dona doces termos!

Melhor nelas gravar seria ofícios palavrosos para um tabelião lê-los com voz de arauto. Melhor se entre tabelas de despesas - nas quais o avaro chora o que gastou elas tivessem fim.

Logo é lógico: em “dúplices” percebo vosso nome e também vosso caráter:

não dá sorte o que é par!

O que, irado, desejar-vos-ei, senão que o tempo vos macere e o mofo 
imundo vos encere?

\section{Referências}

\section{Figura (domínio público)}

ANÔNIMO. Afresco de Páquio Próculo e sua esposa. Disponível em: $<$ http://cir.campania.beniculturali.it/museoarcheologiconazionale/ thematic-views/image-gallery/RA106>. Acesso em: 29 mar. 2016.

\section{Textos}

BENJAMIN, W. A tarefa do tradutor. Trad. Susana Kampff Lages. In: HEIDERMANN, W. (Org.). Clássicos da teoria da tradução: v. I alemão-Português. $2^{\mathrm{a}}$. ed., revisada e ampliada. Florianópolis: UFSC/ Núcleo de Tradução, 2010. p. 201-231.

CAMPOS, H. Ilíada de Homero. Intr. e org. Trajano Vieira. São Paulo: Arx, 2001.

DEZOTTI, M. C. C. Tekhnopaígnion: poesia para ver. In: PIRES, A. D.; FERNANDES, M. L. O. (Org.). Matéria de poesia: crítica e criação. São Paulo: Cultura Acadêmica, 2010. p. 15-32.

IRIGOIN, J. Le livre grec des origines à la Renaissance. Paris: BNF, 2001.

MCKEOWN, J. C. Ovid “Amores”: text, prolegomena and commentary. Leeds: Francis Cairns Publications, 1989 [v. II (a commentary on book one)].

OVIDE. Tristes. Texte établi et traduit par Jacques André. Paris: Les Belles Lettres, 1987.

OVIDIUS NASO, P. Carmina amatoria. Ed. Antonio Ramírez de Verger. München/Leipzig: Verlag, 2006 (Bibliotheca Scriptorum Graecorum et Romanorum Teubneriana).

PATON, W. The Greek Anthology: books I-VI. Cambridge, Massachusetts/ London: Harvard University Press, 1993 [1916]. 
PRADO, J. B. T. Canto e encanto, o charme da poesia latina: contribuição para uma poética da expressividade em língua latina. 1997. 272ff. Tese (Doutorado em Letras Clássicas) - Faculdade de Filosofia, Letras e Ciências Humanas da Universidade de São Paulo, 1997.

THAMOS, M. Propércio, I 1; I 2; I 7; I 12: algumas elegias do livro de Cíntia. Letras Clássicas, São Paulo, n. 10 [2006], p. 215-224, 2011.

STAROBINSKI, J. As palavras sob as palavras: os anagramas de Ferdinand Saussure. Trad. Carlos Vogt. São Paulo: Perspectiva, 1974.

VEYNE, P. (Org.). História da vida privada: v. I - do Império Romano ao ano mil. Trad. H. Feist. São Paulo: Companhia das Letras, 2009.

VIRGÍliO. Bucólicas. Trad. Raimundo Carvalho. Belo Horizonte: Tessitura/Crisálida, 2005. 